OPEN ACCESS

Edited by:

Luo Zhe,

Fudan University, China

Reviewed by:

$\mathrm{Bo} \mathrm{Hu}$,

Zhongnan Hospital of Wuhan

University, China

Ping Chang,

Southern Medical University, China

*Correspondence:

Yamin $\mathrm{Li}$

aminny@csu.edu.cn

Bo Yu

yuboicu@csu.edu.cn

tThese authors have contributed equally to this work and share first authorship

Specialty section:

This article was submitted to

Intensive Care Medicine and

Anesthesiology,

a section of the journal

Frontiers in Medicine

Received: 04 August 2021 Accepted: 20 September 2021

Published: 26 October 2021

Citation:

Wang $H Q$, Deng $S Q$, Fan $X Y$, Li JX,

Tang L, Li YM and Yu B (2021)

Research Trends and Hotspots of

Extracorporeal Membrane

Oxygenation: A 10-Year Bibliometric

Study and Visualization Analysis.

Front. Med. 8:752956.

doi: 10.3389/fmed.2021.752956

\section{Research Trends and Hotspots of Extracorporeal Membrane Oxygenation: A 10-Year Bibliometric Study and Visualization Analysis}

\author{
Huaqin Wang ${ }^{1 \dagger}$, Siqi Deng ${ }^{2 \dagger}$, Xiaoyu Fan ${ }^{3}$, Jinxiu $\mathrm{Li}^{4}$, Li Tang ${ }^{1}$, Yamin $\mathrm{Li}^{{ }^{*}}$ and Bo $\mathrm{Yu}^{4 *}$ \\ ${ }^{1}$ Clinical Nursing Teaching and Research Section, The Second Xiangya Hospital of Central South University, Changsha, \\ China, ${ }^{2}$ College of Nursing, Hunan University of Traditional Chinese Medicine, Changsha, China, ${ }^{3}$ College of Medicine, \\ Jishou University, Jishou, China, ${ }^{4}$ Department of Critical Care Medicine, The Second Xiangya Hospital of Central South \\ University, Changsha, China
}

Objective: To determine the research hotspots and trends in the field of extracorporeal membrane oxygenation (ECMO), and to provide a reference for further and wider research in the future.

Methods: The literatures on ECMO from January 2011 to July 2021 in the Web of Science Core Collection (WOSCC) database were searched, and Citespace5.8.R1 software was used to conduct bibliographic and visual analysis on the literature by country, institution, author and keywords.

Results: A total of 5,986 articles were enrolled. According to an observation, the number of articles published in the past decade has increased, especially from 2019 to 2020. The USA had the largest number of publications, while less ECMO related studies were conducted among non-developed countries. The University of Michigan (Univ Michigan) was the institution that had the largest number of publications and the highest centrality, and Daniel B was the author who had the largest number of publications. However, more inter-institutional cooperation among author teams was needed. The focus of existing ECMO research has primarily been on the treatment of patients suffering from severe cardiopulmonary failure, and the prevention and management of complications during the application ECMO.

Conclusion: Inter-regional and inter-institutional cooperation and exchanges should be carried out among ECMO research teams and institutions. The suggested research direction is to further broaden the application scope of ECMO, while determining the ways to reduce the incidence of complications and the cost, cultivate specialized team talents, and promote the application thereof.

Keywords: ECMO, visualization analysis, bibliometric study, research trends and hotspots, COVID-19 


\section{INTRODUCTION}

Extracorporeal membrane oxygenation (ECMO), an artificial in vitro support system, is commonly used to treat refractory heart and respiratory failure $(1,2)$. As a form of extracorporeal life support system, ECMO can support the respiratory function of patients with respiratory failure, so as to alleviate circulatory hypoxemia in patients developing cardiopulmonary failure. Therefore, the function of ECMO is not limited to extracorporeal circulation support. ECMO has been extensively applied in clinical cardiac surgery, respiratory diseases and critical care medicine for the past 50 years. In particular, the outbreak of Coronavirus disease 2019 (COVID-19) in late 2019 has posed a significant threat to human health and a huge challenge for global public health security $(3,4)$. ECMO plays an important role in saving lives as a rescue therapy for COVID19 patients (5-7). Due to the precise therapeutic effects thereof, ECMO technology has become mature in clinical practices rapidly, and a large number of studies have been performed at the same time. Bibliometrics, an interdisciplinary science, involves mathematical and statistical tools to identify trends, as well as research themes or areas of focus $(8,9)$. In bibliometrics, based on multiple indicators such as references, authors, journals, countries and institutions, visualizations are generated, which provides an in-depth assessment of thematic trends and priorities in a given field (10-12). Most previous studies on ECMO have centered on theoretical research and experience sharing. Meanwhile, quantitative and visual analysis methods have not been adopted to explore the vertical and horizontal characteristics, development and multiple impacts of the present topic. As such, in the present study, the bibliometric analysis software (CiteSpace) was used to conduct statistics and analysis of ECMO related literatures in the past 10 years, and to generate visual graphics for the exploration of the hot spots and future development trends in the present research field, so as to facilitate further research in the future.

\section{METHODS}

\section{Data Acquisition and Search Strategy}

Web of Science Core Collection (WOSCC) was used as the source for retrieval and screening, with literatures on ECMO from January 2011 to July 2021 being retrieved. The key words included "Extracorporeal Membrane Oxygenation" and "ECMO." The inclusion criteria included literatures with "ECMO" as the main research content. The exclusion criteria are as follows: newspapers; advertisements; scientific and technological achievements; books and conference papers; repeated publications; and literature with incomplete information. The subjects and abstracts were read independently in pairs and screened on the basis of inclusion and exclusion criteria. If the title and abstract of a study could not be determined, the full text was read, and then a third researcher would be consulted to help decide whether such study should be included or not.

\section{Analysis Software}

The included literatures were exported in TEXT format, and then imported into Citespace5.8.R1 software that was used for data visualization analysis and bibliometric analysis. The overall visual analysis process was shown in Figure 1. The span of literature in the present study was selected as 1 year. By adjusting corresponding parameters, co-occurrence analysis, cluster analysis and visualization map were performed for countries, authors, institutions and keywords. Frequency was applied to represent the number of countries, institutions and authors. To measure the importance of nodes in the network, the centrality was used, with a higher centrality representing a higher degree of importance. Different nodes in the visualization represent different countries/regions, institutions, authors, or keywords. The size of the node marks the frequency or centrality of the literature. A line between nodes refers to a cooperative network.

\section{Statistical Methods}

Frequency, the main metric, was used to identify the core countries/territories, institutions, authors, and keywords. Centrality means betweenness centrality that is an indicator to measure the importance of nodes in the network. This indicator was used by Citespace to discover and measure the significance of various kinds of literatures and purple circles were utilized to highlight such literatures. Pieces of literatures with high betweenness centrality were usually the key hubs connecting two different fields. It is also called a turning point in Citespace. This method of calculating the importance of nodes was proposed by Freeman in 1977. Betweenness centrality is calculated as follows:

$$
B C_{\mathrm{i}}=\sum_{\mathrm{s} \neq i \neq t} \frac{n_{s t}^{i}}{g_{s t}}
$$

In the formula, $g_{s t}$ is the number of shortest paths from node $s$ to node $t$, and means the number of shortest paths through node i among $g_{s t}$ shortest paths from node $s$ to node t. From the perspective of information transmission, the higher the betweenness centrality is, the greater the importance of the node is. The result of clustering analysis is a keyword co-occurrence network. The cluster view emerges the distribution of fields from a different point of view. The timeline view primarily reveals solicitude to delineate the relationship between clustering results and concentrates on the historical span of literatures in a clustering result.

\section{RESULTS}

A total of 9,806 studies were obtained through preliminary retrieval, and 5,986 studies were included after screening according to the inclusion and exclusion criteria.

\section{Annual Publication Trend of Literature}

In the past 10 years, the number of published studies on ECMO exhibited an overall upward trend, especially during the period from 2019 to 2020 (Table 1; Figure 2). The number of literatures published in 2020 was five times that of 2011 due to the outbreak 


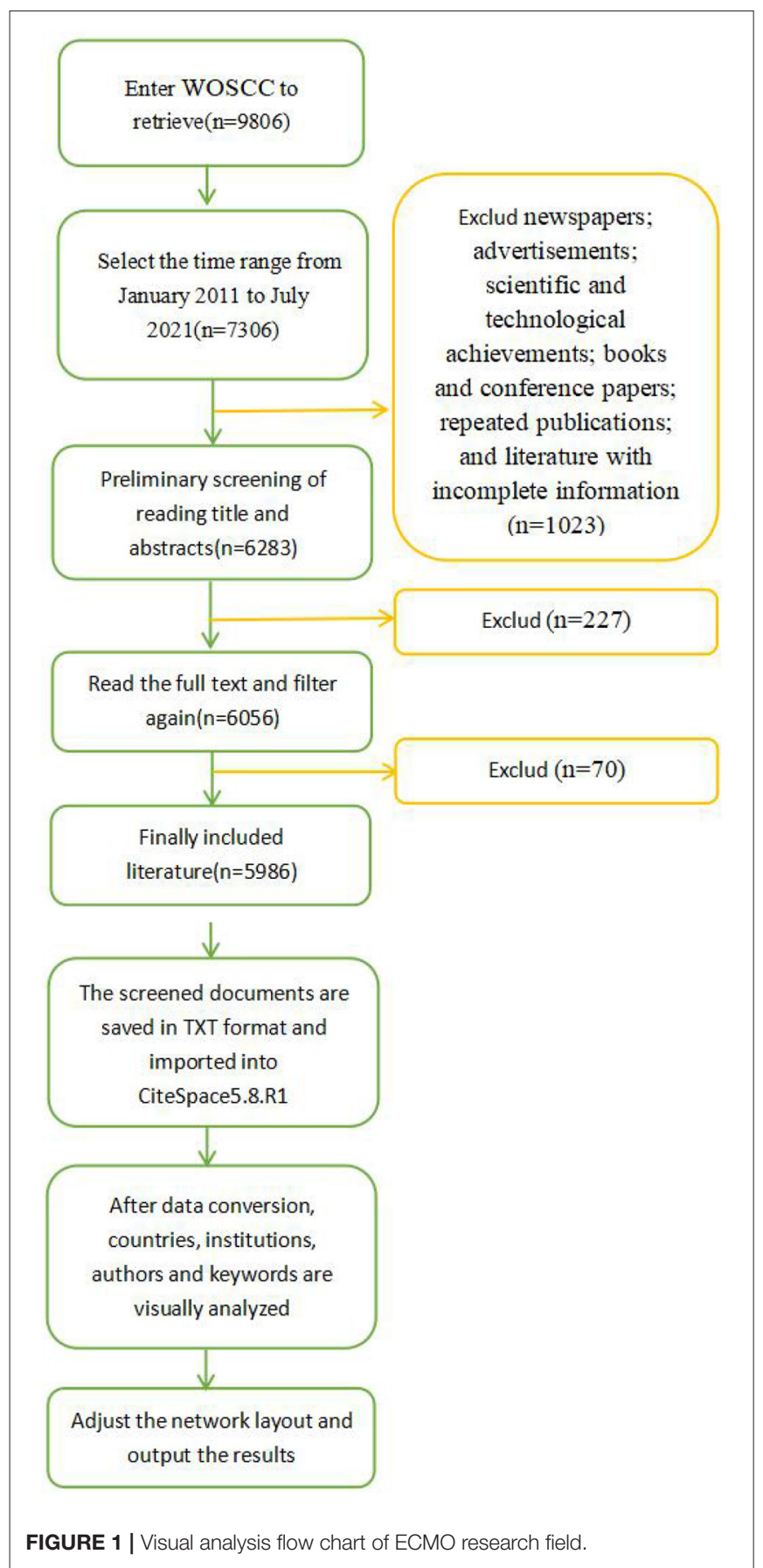

of COVID-19 in late 2019. ECMO has obtained worldwide attention as an effective treatment, and extensive studies have been conducted on the indications and efficacy thereof.

\section{State Issuance of Documents}

According to the frequency of publication and centrality, the countries that published the included literatures were analyzed and ranked, respectively. The top 10 countries were listed in Table 2, in which the USA ranked the first in the frequency of
TABLE 1 | Literature annual distribution.

\begin{tabular}{lcc}
\hline Year of publication & Record & \% of 5,986 \\
\hline 2021 & 736 & 12.30 \\
2020 & 1,191 & 19.90 \\
2019 & 768 & 12.83 \\
2018 & 704 & 11.76 \\
2017 & 588 & 9.83 \\
2016 & 516 & 8.62 \\
2015 & 451 & 7.53 \\
2014 & 313 & 5.23 \\
2013 & 297 & 4.96 \\
2012 & 220 & 3.68 \\
2011 & 202 & 3.37 \\
\hline
\end{tabular}

publication and centrality. Each node in the country visualization map represents a country, the size of the node stands for the amount of output, and the lines between the nodes are the partnerships between countries (Figure 3).

\section{Institutional Publication Status}

Research institutions were ranked by publication frequency and centrality, and an institution visualization map was created (Figure 4). The top 10 institutions are listed in Table 3, in which the University of Michigan (Univ Michigan) ranked first with 144 papers, and also ranked first with 0.13 centrality.

\section{Author Publication Status}

The authors were ranked by publication frequency and centrality, and an author visualization map was created (Figure 5). The top 10 authors are shown in Table 4 , in which the results reveal that Daniel B ranked first with a publication frequency of 73 and a centrality of 0.13 .

\section{Keywords Clustering Timeline and Keyword Bursts}

Cluster analysis was formed on the basis of keyword cooccurrence, and seven clusters were formed in total: acute respiratory distress syndrome, pharmacokinetics, cardiogenic shock, anticoagulation, congenital diaphragmatic hemia, lung transplantation, and cardiac arrest. TimeLine View was used to draw a timeline for keywords after clustering, and the length of the horizontal line corresponding to each cluster represents the time span of the cluster, as shown in Figure 6. TimeLine View mainly reveals the relationship between description clustering results, and focuses on the historical span of literature in the clustering results. CiteSpace was further used to detect bursts of keywords with high frequency, as shown in Figure 7.

\section{DISCUSSION}

\section{Analysis of Countries}

In the present study, the top 10 countries in ECMO related fields were found to be mainly developed countries such as the United States, Germany, Italy and others. Both in terms 


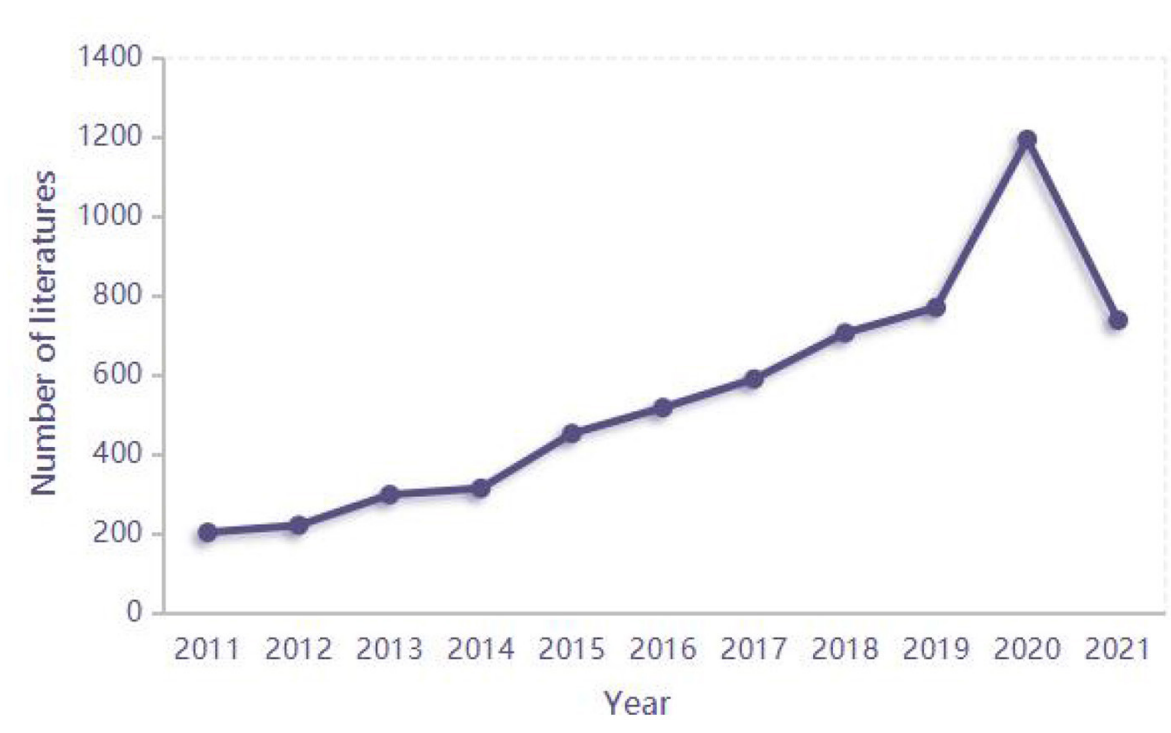

FIGURE 2 | Annual publications.

TABLE 2 | Top 10 countries by publication frequency and centrality.

\begin{tabular}{llcll}
\hline No. & Country & Frequency & Country & Centrality \\
\hline 1 & USA & 1,882 & USA & 0.22 \\
2 & Germany & 646 & France & 0.16 \\
3 & Italy & 384 & Italy & 0.14 \\
4 & China & 313 & England & 0.12 \\
5 & France & 304 & Germany & 0.10 \\
6 & England & 241 & Japan & 0.07 \\
7 & South Korea & 234 & Australia & 0.05 \\
8 & Japan & 233 & Canada & 0.04 \\
9 & Australia & 223 & China & 0.01 \\
10 & Canada & 188 & South Korea & 0.00
\end{tabular}

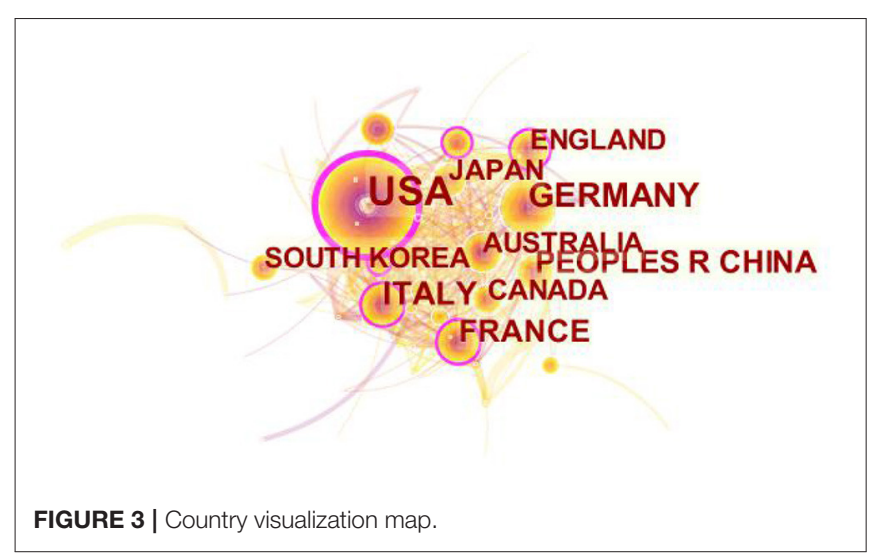

of quantity and quality, developed countries have obvious advantages in research strength. At the same time, the problem of geographical imbalance in research is also reflected. Only three Asian countries, China, Japan and South Korea, were in the top 10 list (Table 2). Studies have shown that despite being effective,

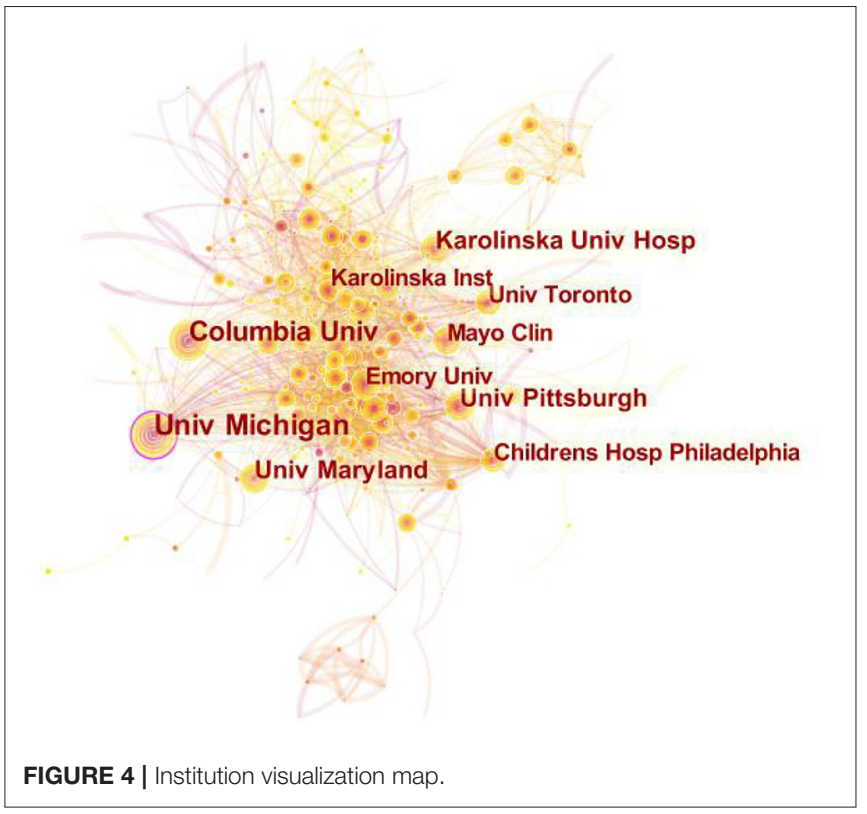

ECMO is considerably expensive (13). A study in Turkey also revealed that current ECMO resources are inadequate (14). Hence, ECMO related studies are rarely conducted in nondeveloped countries, which may be related to the high cost of ECMO. The economic strength of hospitals in non-developed countries is insufficient, and the economic bearing capacity of the majority of patients is also low, so the promotion is difficult to some extent.

\section{Analysis of Authors and Institutions}

The results reveal that many authors collaborated closely with each other and formed several research teams. Among those teams, the top two research teams of Daniel B and 
Alain $\mathrm{C}$ both focused on the treatment and management of acute respiratory distress syndrome (ARDS) with ECMO. From the perspective of the cooperative network of scientific research institutions, Univ Michigan and Columbia University

TABLE 3 | Top 10 institutions by publication frequency and centrality.

\begin{tabular}{llclc}
\hline No. & Institution & Frequency & Institution & Centrality \\
\hline 1 & Univ Michigan & 144 & Univ Michigan & 0.13 \\
2 & Columbia Univ & 124 & Univ Toronto & 0.08 \\
3 & Univ Maryland & 81 & $\begin{array}{l}\text { Childrens Hosp } \\
\text { Philadelphia }\end{array}$ & 0.07 \\
& Karolinska Univ & 75 & Univ Pittsburgh & 0.06 \\
4 & Hosp & & Columbia Univ & 0.04 \\
5 & Univ Pittsburgh & 74 & Emory Univ & 0.04 \\
6 & Univ Toronto & 73 & Karolinska Inst & 0.03 \\
7 & Emory Univ & 68 & Karolinska Univ & 0.02 \\
8 & Karolinska Inst & 67 & Hosp & 0.02 \\
9 & Childrens Hosp & 64 & Mayo Clin & \\
& Philadelphia & & Univ Maryland & 0.01
\end{tabular}

(Columbia Univ) have conducted more research on ECMO, and the centrality of Univ Michigan ranked first. Such results could be attributed to the strong academic atmosphere, strong scientific research foundation and sufficient funds of the two universities. However, the cooperation between institutions is only limited to the cooperation between institutions and the hospitals with which institutions are closely connected, such as

TABLE 4 | Top 10 authors by publication frequency and centrality.

\begin{tabular}{lllll}
\hline No. & Author & Frequency & Author & Centrality \\
\hline 1 & Daniel B & 73 & Daniel B & 0.13 \\
2 & Alain C & 60 & Alain C & 0.08 \\
3 & Alois P & 50 & Roberto HB & 0.08 \\
4 & Thomas M & 45 & Thomas M & 0.06 \\
5 & Adriano P & 41 & Alois P & 0.04 \\
6 & Guillaumel L & 37 & Adriano P & 0.03 \\
7 & Matthieu S & 36 & Matthieu S & 0.03 \\
8 & Pascal L & 36 & Guillaumel L & 0.01 \\
9 & Matthew B & 33 & Matthew B & 0.01 \\
10 & Roberto HB & 33 & Pascal L & 0.00
\end{tabular}

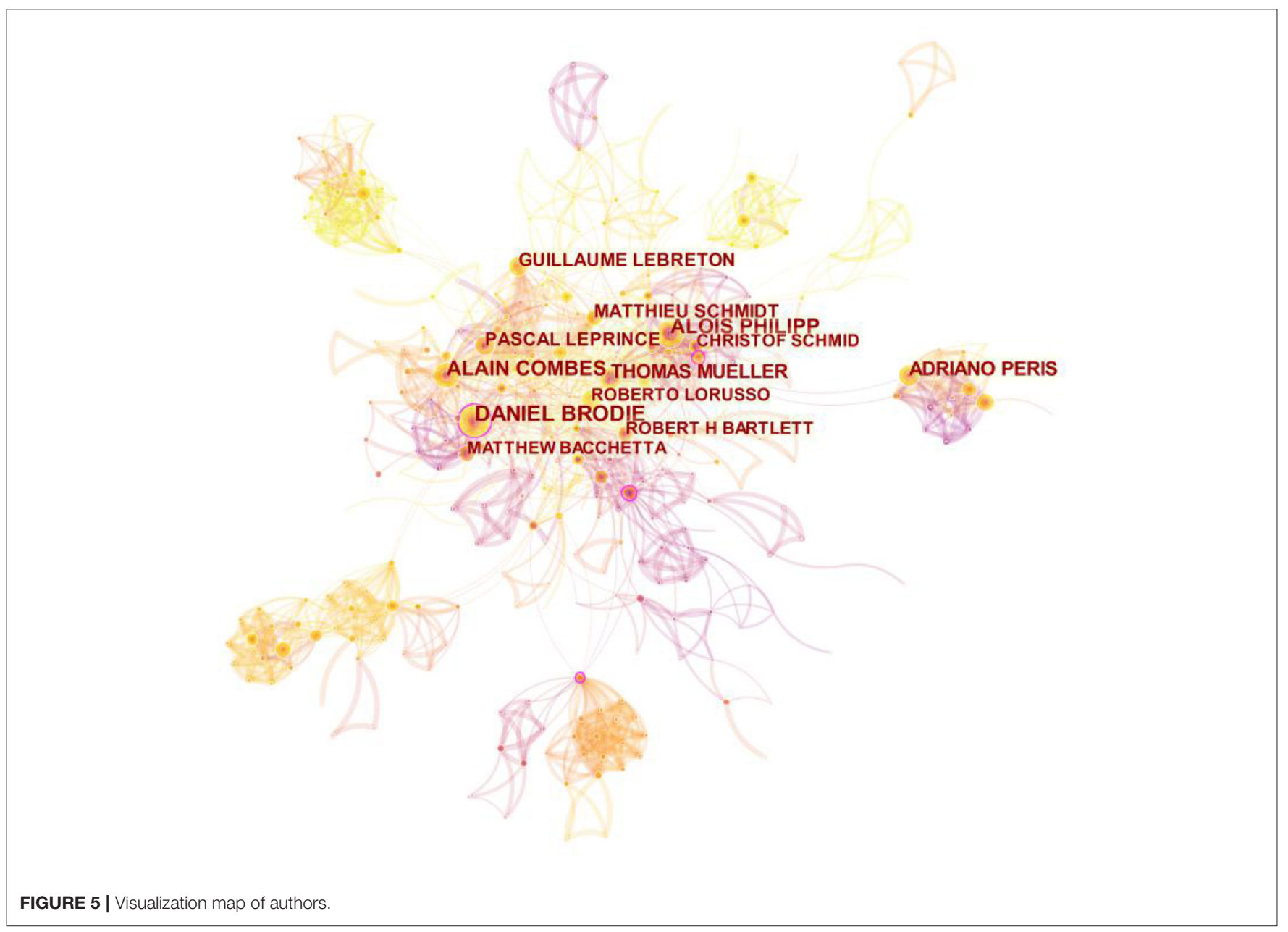




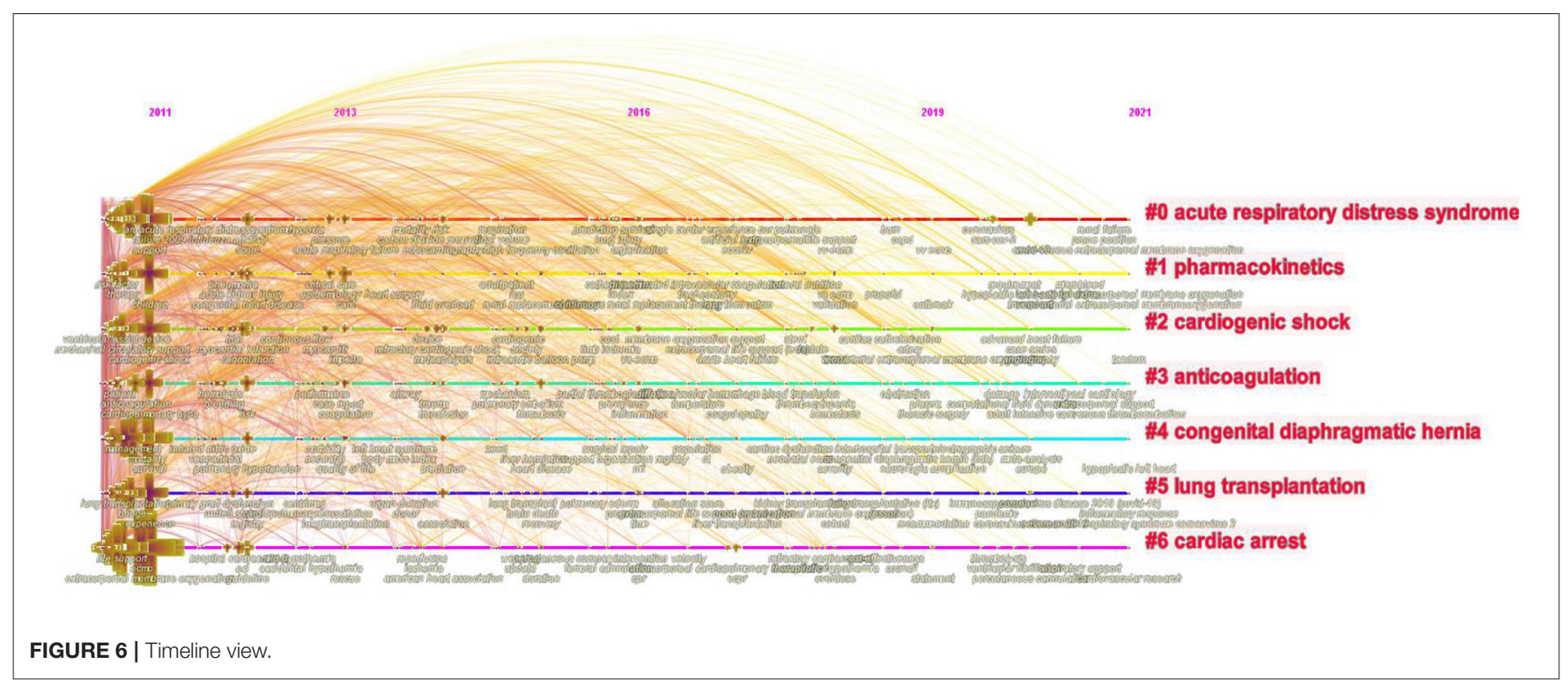

The University of Maryland (Univ Maryland) and Children's Hospital of Philadelphia (Childrens Hosp Philadelphia), while the cooperation between different organizations and institutions is less. As such, the cooperation between different institutions needs to be strengthened. The aforementioned results also reflect that researchers have a weak sense of cooperation between different institutions, and further research on ECMO needs to be further explored.

\section{Research Hotspots Change Greatly Over Time}

According to the timeline view (Figure 6) and burst test of keywords (Figure 7), combined with the number of chronological documents, the research on ECMO can be roughly divided into three stages.

The first phase from 2011 to 2013 was the initial exploration of ECMO, and researchers mostly attached attentions on the initial exploration of ECMO's treatment of children suffering from severe cardiopulmonary diseases and patients with influenza A (H1N1) (15-19). At the beginning of the first phase, many scholars found that ECMO was irreplaceable in the treatment of severe respiratory failure in children with severe illnesses, especially newborns and infants $(20,21)$. However, with the outbreak of H1N1 in 2013, ECMO has become the focus of research, owing to the high fatality rate and the numerous complications such as explosive acute lung injury (ALI) and acute respiratory distress syndrome (9ARDS) (22). ECMO has become a significant factor in reducing patient mortality (23, 24).

In the second phase from 2014 to 2018, ECMO studies exhibited a trend of diversification. ECMO was mainly applied to the treatment of lung transplantation, congenital diaphragmatic hernia and other diseases. For example, Hoetzenecker's (25) team studied the therapeutic effects of ECMO on patients after lung transplantation, while McHoney's (26) team developed the application of ECMO in the treatment of congenital diaphragmatic hernia. At the same time, scholars began to pay attention to various complications that occurred during the application of ECMO (27). The incidence of bleeding and thrombosis as complications is considerably high, and continuous anticoagulation increases the risk of bleeding in patients (28). Some studies have revealed that the incidence of bleeding in adults treated with ECMO is $27-60 \%$. Once severe bleeding events such as intracranial hemorrhage and pulmonary hemorrhage occur, death rate also increases (29). Such complications have significant negative impacts on the quality of patients' life. Determining how to reduce bleeding and prevent the formation of thrombosis has become the top priority in ECMO support therapy $(30,31)$.

In the third phase from 2019 to 2021, there was an explosion on ECMO, mainly due to the emergence of COVID-19 in late 2019, and the resulting pandemic in 2020. Many researchers have applied previous ECMO experience in treating other diseases to the treatment of COVID-19 patients. As a new life support technology, ECMO not only saved the lives of many patients with COVID-19, but also further improved the success rate of treatment and reduced the incidence of complications. Numerous studies $(17,32,33)$ have proved that ECMO is a significant factor in stabilizing and treating survival rates in critically ill COVID-19 patients. Hence, most of the studies in the third phase focused on the exploration and experience of ECMO in the treatment of COVID-19 patients.

\section{Research Trend and Hotspot Thinking}

Understanding the development trend and future trend of a discipline can help us quickly and effectively obtain the latest research hot spots and innovations of relevant disciplines, thus further promoting the efficient development of the discipline. From the salient words and related literatures in recent years, it was obvious that the research focus in this field is single diagnosis and treatment of severe diseases, focusing on the treatment of complications, and gradually deepens into the 


\section{Top 25 Keywords with the Strongest Citation Bursts}

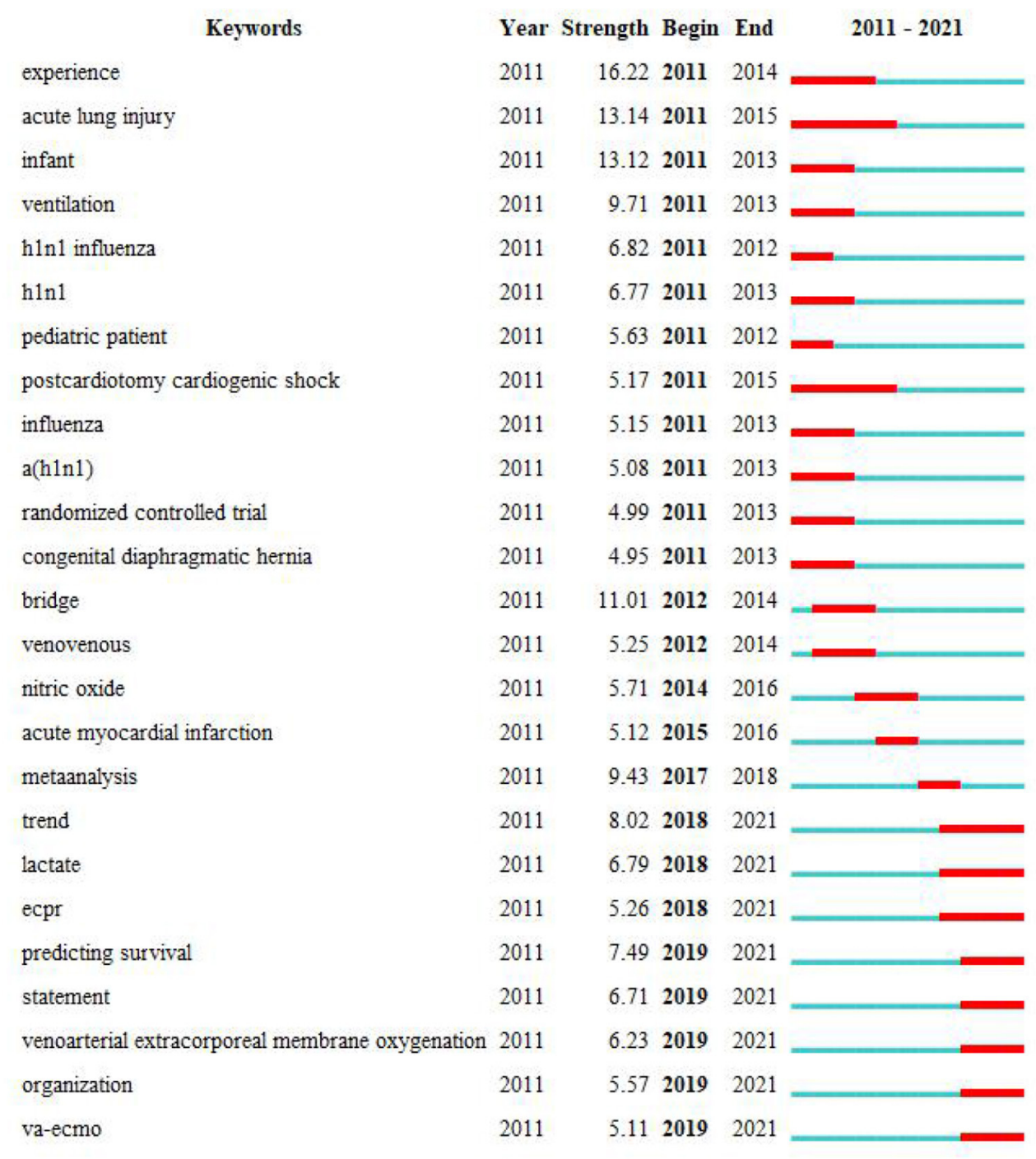

FIGURE 7 | Burst test of keywords.

treatment of multiple diseases. ECMO has been widely used for the treatment of cardiopulmonary diseases that were intractable with conventional treatment for many years. On the other hand, ECMO has played a crucial role in treating severe patients. However, a number of studies $(30,34)$ have demonstrated that ECMO is accompanied with high complications when treating both mechanically ventilated patients and patients in stable stage. The prevention, diagnosis and treatment of complications are always our focus and difficulty, so we should continue to explore these research hotspots in the future. What's more, there is no unified standard for the timing of ECMO use. For example, Diddle et al. (35) proposed that early use of ECMO before severe arrhythmia, heart failure and other abnormal symptoms in patients with acute myocarditis could improve the prognosis. However, some studies have also suggested that the application of ECMO in patients with organ failure such as low $\mathrm{pH}$, high lactic acid, abnormal liver function, and renal dysfunction requiring renal replacement therapy will lead to the reduce of survival rate $(36,37)$. According to the current evidence-based medicine, the optimal application time cannot be determined. The precision of ECMO is also the direction of future research.

Most importantly, although the application and development of ECMO have been promoted by the H7N9 avian influenza in 2013 and the COVID-19 epidemic in 2020, the treatment cost of ECMO still remains high, the technology remains complex, and the treatment varies widely among individuals. Further, ECMO exists high risk, and its scope is limited, 
with some hospitals encountering difficulties in applying such technology. Therefore, how to reduce the cost and improve the portability and mobility will also become the research hotspots and development trends of ECMO. A high-level ECMO team is critical for the improvement of patient's benefit rate. Future research should also pay more attention on the training and establishment of ECMO specialist teams. In the present study, only a single database, namely WOSCC, was retrieved, and other databases were not included. There are several limitations in current ECMO research, and thus, the retrieval scope should be expanded to conduct indepth research.

\section{REFERENCES}

1. Gattinoni L, Carlesso E, Langer T. Clinical review: extracorporeal membrane oxygenation. Crit Care. (2011) 15:243. doi: 10.1186/cc10490

2. Combes A, Hajage D, Capellier G, Demoule A, Lavoué S, Guervilly C, et al. Extracorporeal membrane oxygenation for severe acute respiratory distress syndrome. N Engl J Med. (2018) 378:1965-75. doi: 10.1056/NEJMoa1800385

3. Wang W, Tang J, Wei F. Updated understanding of the outbreak of 2019 novel coronavirus (2019-nCoV) in Wuhan, China. J Med Virol. (2020) 92:4417. doi: $10.1002 / \mathrm{jmv} .25689$

4. WHO. Statement on the Second Meeting of the International Health Regulations. (2005). Emergency Committee regarding the outbreak of novel coronavirus (2019-nCoV) [EB/OL]. Available online at: https://www.scirp. org/reference/referencespapers/aspx/referenceid $\$=\$ 2792187$ (accessed July 24, 2021).

5. Yang X, Cai S, Luo Y, Zhu F, Hu M, Zhao Y, et al. Extracorporeal membrane oxygenation for Coronavirus Disease 2019-induced acute respiratory distress syndrome: a multicenter descriptive study. Crit Care Med. (2020) 48:128995. doi: 10.1097/CCM.0000000000004447

6. Barbaro RP, MacLaren G, Boonstra PS, Iwashyna TJ, Slutsky AS, Fan E, et al. Extracorporeal membrane oxygenation support in COVID-19: an international cohort study of the Extracorporeal Life Support Organization registry. Lancet Resp Med. (2020) 396:1071-8. doi: 10.1016/S0140-6736(20)32008-0

7. Ramanathan K, Shekar K, Ling RR, Wong SN, Tan CS, Rochwerg B, et al. Extracorporeal membrane oxygenation for COVID-19: a systematic review and meta-analysis. Crit Care. (2021) 25:211. doi: 10.1186/s13054-021-03634-1

8. Oelrich B, Peters R, Jung K. A bibliometric evaluation of publications in Urological journals among European Union countries between 2000-2005. Eur Urol. (2007) 52:123. doi: 10.1016/j.eururo.2007.06.050

9. Bornmann L, Leydesdorff L. Scientometrics in a changing research landscape. Embo Rep. (2014) 15:1228-32. doi: 10.15252/embr.201439608

10. Chen $\mathrm{C}, \mathrm{Hu} \mathrm{Z}$, Liu S, Tseng $\mathrm{H}$. Emerging trends in regenerative medicine: a scientometric analysis in CiteSpace. Expert Opin Biol Ther. (2012) 12:593608. doi: 10.1517/14712598.2012.674507

11. Ellegaard $\mathrm{O}$, Wallin JA. The bibliometric analysis of scholarly production: how great is the impact? Scientometrics. (2015) 105:1809-31. doi: 10.1007/s11192-015-1645-Z

12. Wang Q, Yang ZG, Yang Y, Long C, Li H. A bibliometric analysis of research on the risk of engineering nanomaterials during 19992012. Sci Total Environ. (2014) 473:483-9. doi: 10.1016/j.scitotenv.2013. 12.066

13. Oude Lansink-Hartgring A, van Minnen $O$, Vermeulen KM, van den Bergh WM. Hospital costs of extracorporeal membrane oxygenation in adults: a systematic review. Pharmacoecon Open. (2021) 31:1-11. doi: 10.1007/s41669-021-00272-9

14. Han JJ, Shin M, Patrick WL, Rao A, Olia SE, Helmers MR, et al. How should ecmo be used under conditions of severe scarcity? A population study of public perception. J Cardiothorac Vasc Anesth. (2021). doi: 10.1053/j.jvca.2021.05.058. [Epub ahead of print].

\section{DATA AVAILABILITY STATEMENT}

The original contributions presented in the study are included in the article/supplementary material, further inquiries can be directed to the corresponding author/s.

\section{AUTHOR CONTRIBUTIONS}

HW designed this study and collected data. SD performed the search. SD and XF rechecked data. HW and SD performed analysis. YL and BY critically revised the work. All authors contributed to the article and approved the submitted version.

15. Combes A, Bacchetta M, Brodie D, Müller T, Pellegrino V. Extracorporeal membrane oxygenation for respiratory failure in adults. Curr Opin Crit Care. (2012) 18:99-104. doi: 10.1097/MCC.0b013e32834ef412

16. Quintel M, Bartlett RH, Grocott MPW, Combes A, Ranieri MV, Baiocchi $\mathrm{M}$, et al. Extracorporeal membrane oxygenation for respiratory failure. Anesthesiolog. (2020) 132:1257-76. doi: 10.1097/ALN.0000000000003221

17. Saeed O, Tatooles AJ, Farooq M, Schwartz G, Pham DT, Mustafa AK, et al. Characteristics and outcomes of patients with COVID-19 supported by extracorporeal membrane oxygenation: a retrospective multicenter study. $J$ Thorac Cardiovasc Surg. (2021). doi: 10.1016/j.jtcvs.2021.04.089. [Epub ahead of print].

18. Itoh H, Ichiba S, Ujike Y, Kasahara S, Arai S, Sano S. Extracorporeal membrane oxygenation following pediatric cardiac surgery: development and outcomes from a single-center experience. Perfusion. (2012) 27:2259. doi: 10.1177/0267659111434857

19. Pham T, Combes A, Rozé H, Chevret S, Mercat A, Roch A, et al. Extracorporeal membrane oxygenation for pandemic influenza A(H1N1)induced acute respiratory distress syndrome: a cohort study and propensity-matched analysis. Am J Respir Crit Care Med. (2013) 187:276-85. doi: 10.1164/rccm.201205-0815OC

20. Wildschut ED, Ahsman MJ, Houmes RJ, Pokorna P, de Wildt $\mathrm{SN}$, Mathot RA, et al. Pharmacotherapy in neonatal and pediatric extracorporeal membrane oxygenation (Ecmo). Curr Drug Metab. (2012)13:767-77. doi: 10.2174/138920012800840383

21. Salerno JC, Seslar SP, Chun TU, Vafaeezadeh M, Parrish AR, Permut LC, et al. Predictors of Ecmo support in infants with tachycardia-induced cardiomyopathy. Pediatr Cardiol. (2011) 32:754. doi: 10.1007/s00246-011-9961-4

22. Jaber S, Conseil M, Coisel Y, Jung B, Chanques G. [Ards and Influenza A(H1n1): patients' characteristics and management in intensive care unit. A literature review. Ann Fr Anesth Reanim. (2010) 29:117-25. doi: 10.1016/j.annfar.2009.12.026

23. Haeck JD, Dongelmans DA, Schultz MJ. ECMO centers and mortality from Influenza A(H1N1). JAMA. (2012) 307:454. doi: 10.1001/jama.2012.57

24. Cianchi G, Bonizzoli M, Pasquini A, Bonacchi M, Zagli G, Ciapetti M, et al. Ventilatory and ECMO treatment of H1N1-induced severe respiratory failure: results of an Italian referral ECMO center. BMC Pulm Med. (2011) 11:2. doi: 10.1186/1471-2466-11-2

25. Hoetzenecker K, Schwarz S, Muckenhuber M, Benazzo A, Frommlet F, Schweiger $\mathrm{T}$, et al. Intraoperative extracorporeal membrane oxygenation and the possibility of postoperative prolongation improve survival in bilateral lung transplantation. J Thorac Cardiovasc Surg. (2018) 155:2193206.e3. doi: 10.1016/j.jtcvs.2017.10.144

26. McHoney M, Hammond P. Role of ECMO in congenital diaphragmatic hernia. Arch Dis Child Fetal Neonatal Ed. (2018) 103:F178-81. doi: 10.1136/archdischild-2016-311707

27. Xia W, Xu H, Mao W, Chen J. Extracorporeal membrane oxygenation as a bridge to lung transplantation. Zhonghua Wei Zhong Bing Ji Jiu Yi Xue. (2018) 30:1167-72. doi: 10.3760/cma.j.issn.2095-4352.2018.0 12.013 
28. Murphy DA, Hockings LE, Andrews RK, Aubron C, Gardiner EE, Pellegrino VA, et al. Extracorporeal membrane oxygenation-hemostatic complications. Transfus Med Rev. (2015) 29:90-101. doi: 10.1016/j.tmrv.201 4.12 .001

29. Mazzeffi MA, Tannaka K, Roberts A, Rector R, Menaker J, Kon Z, et al. Bleeding, thrombosis, and transfusion with two heparin anticoagulation protocolsin venoarterial ECMO patients. J Cardiothorac Vasc Anesth. (2019) 33:1216-122. doi: 10.1053/j.jvca.2018.07.045

30. Cheng R, Hachamovitch R, Kittleson M, Patel J, Arabia F, Moriguchi J, et al. Complicationgs of extracorporeal membrane oxygenation of treatment of cardiogenic shock and cardiac arrest: a meta-analysis of 1,866 adult patients. Ann Thorac Surg. (2014) 97:610-6. doi: 10.1016/j.athoracsur.201 3.09 .008

31. Thomas J, Kostousov V, Teruya J. Bleeding and thrombotic complications in the use of extracorporeal membrane oxygenation. Semin Thromb Hemost. (2018) 44:20-9. doi: 10.1055/s-0037-1606179

32. Hu BS, Hu MZ, Jiang LX, Yu J, Chang Y, Cao Y, et al. Extracorporeal membrane oxygenation (ECMO) in patients with COVID-19: a rapid systematic review of case studies. Eur Rev Med Pharmacol Sci. (2020) 24:11945-52. doi: 10.26355/eurrev_202011_23855

33. Daniela M, Felipe S, Van Nicolette SJ, Tomás R, Eli V, Jorge R, et al. Mobile ECMO in COVID-19 patient: case report. J Artif Organs. (2021) 24:28792. doi: 10.1007/s10047-020-01209-5

34. Combes A, Leprince P, Luyt CE, Bonnet N, Trouillet JL, Leger P, et al. Outcomes and long-term quality-of-life of patients supported by extracorporeal membrane oxygenation for refractory cardiogenic shock. Crit Care Med. (2008) 36:1404-11. doi: 10.1097/CCM.0b013e31816f7cf7

35. Diddle JW, Almodovar MC, Rajagopal SK, Rycus PT, Thiagarajan RR. Extracorporeal membrane oxygenation for the support of adults with acute myocarditis. Crit Care Med. (2015) 43:101625. doi: 10.1097/CCM.0000000000000920

36. Aubron C, Cheng AC, Pilcher D, Leong T, Magrin G, Cooper D J, et al. Factors associated with outcomes of patients on extracorporeal membrane oxygenation support: a 5-year cohortstudy. Crit Care. (2013) 17:R73. doi: 10.1186/cc12681

37. Demondion P, Fournel L, Golmard JL, Niculescu M, Pavie A, Leprince P. Predictors of 30-day mortality and outcome in cases of myocardial infarction with cardiogenic shock treated by extracorporeal life support. Eur J Cardiothorac Surg. (2014) 45: 47-54. doi: 10.1093/ejcts/ezt207

Conflict of Interest: The authors declare that the research was conducted in the absence of any commercial or financial relationships that could be construed as a potential conflict of interest.

Publisher's Note: All claims expressed in this article are solely those of the authors and do not necessarily represent those of their affiliated organizations, or those of the publisher, the editors and the reviewers. Any product that may be evaluated in this article, or claim that may be made by its manufacturer, is not guaranteed or endorsed by the publisher.

Copyright (C) 2021 Wang, Deng, Fan, Li, Tang, Li and Yu. This is an open-access article distributed under the terms of the Creative Commons Attribution License (CC $B Y)$. The use, distribution or reproduction in other forums is permitted, provided the original author(s) and the copyright owner(s) are credited and that the original publication in this journal is cited, in accordance with accepted academic practice. No use, distribution or reproduction is permitted which does not comply with these terms. 